\title{
Prediction of Cutting Forces in Ball-End Milling of Multi-Layered Metal Materials
}

\author{
Uroš Župerl* - Franci Čuš - Tomaž Irgolič \\ University of Maribor, Faculty of Mechanical Engineering, Slovenia
}

This paper outlines the experimental exploration of cutting forces produced during ball-end milling of multi-layered metal materials manufactured by the laser engineered net shaping (LENS) process. The research employs an artificial neural network (ANN) technique for predicting the cutting forces during the machining of $16 \mathrm{MnCr} 5 / 316 \mathrm{~L}$ four-layered metal material with a solid carbide ball-end mill. Hardness and thickness of the particular manufactured layer in above mentioned advanced material have been considered during training of the ANN model. Model predictions were compared with experimental data and were found to be in good agreement. Experimental results demonstrate that this method can accurately predict cutting force within a maximum prediction error of $4.8 \%$.

Keywords: end milling, cutting forces, multi-layered material, LENS, ANN

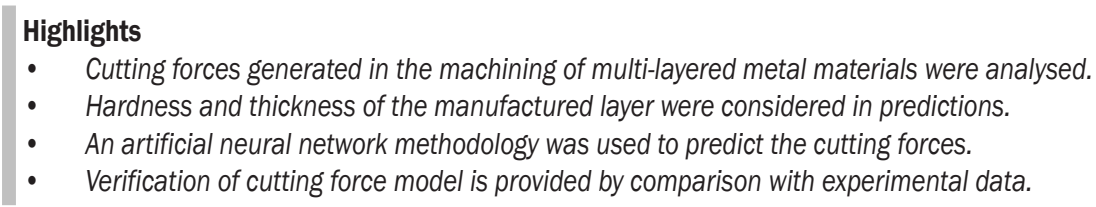

\section{INTRODUCTION}

End milling of multi-layered metal materials is an important manufacturing function in the automotive tool making industry. The most well-known process to fabricate the multi-layered materials was developed by Sandia National Laboratories and is known as laser engineered net shaping (LENS). The company Optomec makes and sells equipment based on Sandia's LENS process. LENS uses a laser power of up to $4 \mathrm{~kW}$ to fuse metal powders into threedimensional structures layer by layer, guided by a CAD model. The process is enclosed in an airtight, argon environment which prevents oxidation. The closed-loop process controls ensure the geometric and mechanical integrity of the completed part [1]. Due to the inhomogeneous structure of multi-layered metal materials manufactured with the LENS process, the machining of these materials leads to undesirable effects such as tool breakage, rapid cutting tool wear, surface deterioration and shelling of the cladded layers (delayerization). All of these undesirable effects are directly connected to the cutting tool forces acting on the workpiece. Delayerization of material is tightly related to the cutting force normal to the layer deposition plane [2]. Cutting forces can be seen as a control parameter for many other phenomena involved in the milling of these materials. Therefore, there is a considerable practical interest to analyse and predict precisely the cutting forces during milling of multilayered metal materials. Knowing the cutting forces is fundamental for understanding the cutting processes, optimizing the milling operations and evaluating the presence of instabilities that could affect the effectiveness of milling processes.

Many cutting force models have been developed for ball-end milling processes, especially the mechanistic models, including the work of Sui [3], Zhou [4] and Milfelner [5]. Mechanistic models try to relate the cutting forces to the chip geometry by experimentally determined cutting force coefficients. The major problem is the lack of cutting force coefficients for oblique cutting and for different tool/workpiece combinations, such as multi-layered laser based metal deposition (LBMD) materials. The coefficients are obtained by labour intensive and timeconsuming cutting experiments and adjusting of model parameters. The problem is even more complicated due to the highly nonlinear and inhomogeneous nature of multi-layer LBMD materials as compared with metals. For these reasons, the generation of specific cutting energy data for LBMD materials is more challenging. No evidence of research efforts that attempts to model the cutting forces in milling LBMD materials has been found. Additionally, the obtained models are also difficult to extend to different tooling systems, conditions, and parameters.

An artificial neural network (ANN) can be used as an alternative to analytical approaches. The method has become widespread in the predictive modelling of milling processes [6] to [8]. ANNs determine an implicit relationship between the input(s) and output(s) 
by learning from a training data set that represents the behaviour of a process. Zuperl [9] proposed a multilevel perceptron for on-line modelling of forces in ball-end milling. Das et al. [10] developed an ANN model to predict the surface roughness generated while machining a metal matrix composite. Dave et al. [11] also proposed a modified back-propagation ANN, which adjusts its learning rate and adds a dynamic factor in the learning process for the on-line modelling of the milling system. Mounayri et al. [12] replaced the back-propagation neural network with a new, more efficient and practical RBM neural network which is finally successfully implemented for the case of ballend milling. Nevertheless, it should be mentioned that according to Navarro at al [13] the ANNs cannot produce better results than statistical methods when stochastic events are analysed. As a result, the ANN techniques in metal cutting are used less and less. Instead, intelligent statistical methods, such as the group method of data handling, are used.

This research employs a feedforward neural network in order to obtain a predictive cutting force model for the milling of four-layered metal material. The ANN predictive capabilities are used to capture the highly nonlinear relationship between machining parameters, tool angle rotation, LENS process parameters, and sensor readings.

The proposed method offers advantages such as automatic searching for the non-linear connection between the inputs and outputs, and no required knowledge of internal system parameters. The computational complexity of model does not increase much with the complexity of process, mathematically modelling-free and simple extending of the model with new input parameters and new data without modifying the existing model structure.

The most significant advantage of the proposed method is that once the experimental data are obtained and arranged, the prediction model for a specific tooling system can be built in a few minutes through training without any knowledge of statistics, machining cutting theory and programming.

By pressing a button in the application software, the processed data from experimental tests and corresponding parameters are automatically arranged in datasets for training and testing, then training and validating of the predefined architecture of ANN is performed. The validated neural model is then capable of predicting the cutting forces in end milling of specific multi-layered metal material.

This makes the proposed method more practical and appropriate for industrial application than predictive models based on cutting force coefficients.
The main drawback of the laser cladding process is the lack of knowledge about the machinability of the metal deposited materials. For LBMD materials, it is difficult to gather data related to the influence of the laser-cladding parameters on the produced cutting forces, flank wear, and surface roughness. Published research relating to the machinability of these materials is extremely scarce. Nevertheless, there are a few studies about the machinability of difficult-tomachine metal deposited materials, such as nickelbased alloys, titanium alloys, and composites. M'Saoubi [14] provided industrial perspectives in the context of machinability of specific alloys used in aerospace applications. He stated that the machinability of aerospace materials should be considered in much broader terms than machining tests that are directed at the tool performance/ material removal rates. A group of researchers carried out mechanical [15] and machinability [14] assessment of a nickel-based superalloy (Inconel 718) in machining operations. Shokrani et al. [16] have reviewed and identified difficult-to-machine materials such as alloys used in the aerospace, nuclear and medical industries. Koyilada et al. [17] performed an evaluation of machinability characteristics of Nimonic C-263 using chemical vapour deposition (CVD) and physical vapour deposition (PVD) coated tools. Dong et al. [18] studied the chip formation during machining of nickel-based alloy Inconel 718 by observing chip metallographic graph. In this research, an experimental investigation was carried out to realize the machinability behaviour of the four-layered metal material in terms of the nature of the cutting force generated while performing the machining operation.

\section{PREDICTIVE CUTTING FORCE MODELING}

The aim of this research is to develop a methodology for predicting the cutting forces produced during ball-end milling of four-layered metal materials. This chapter outlines the adaptation of the ANN topology to the cutting force prediction problem. To carry out the modelling of the three cutting force components, a popular, three-layer architecture of feedforward neural network is used based on the back propagation learning algorithm. The developed ANN has seven input neurons for modelling: spindle speed $n$, feed rate $f$, axial depth of cutting $A_{D}$, radial depth of cutting $R_{D}$, the angle of cutting tool rotation $\Theta$, cutting tool diameter $D$, the hardness of the machined material $H V$ and the thickness of manufactured layer $d$. The number of hidden layers, the optimum number of neurons in the individual hidden layer and the training parameters 
were determined by simulations. The optimum ANN contains 3 and 6 neurons in hidden layers. The output from the ANN are three cutting force components; therefore, three output neurons are necessary. Signals passed through the neurons in the hidden and output layers are transformed by an ArcTangent activation function. Fig. 1 shows the detailed topology of the developed ANN-based cutting force prediction model.

Four steps are required to develop an ANN based cutting force model. In Step 1, the training and testing data sets were introduced to the ANN. A total of 525 scaled data points were utilized as the inputs and outputs to train the ANN.

Table 1 presents a list of 81 data sets (LENS test no. 6) used for training and testing of the ANN; $28 \%$ of these data (highlighted sets) were used for ANN testing to verify the accuracy of the predicted values. Table 1 lists $11 \%$ of the total 729 datasets (Table 2) obtained in the LENS end milling tests for the purpose of ANN modelling. The columns of Table 1 represent the ANN data set number, input vector, and output vector. The ANN topology and training parameters were defined in Step 2. A number of hidden layers, the number of neurons, momentum rate $(\beta)$, learning rate $(\alpha)$, the overall error of the network and the maximal number of training iterations is defined. To evaluate the individual effects of training parameters on the performance of ANN 42 different networks were trained, tested and analysed. The ANN performances were evaluated using the two different criteria: average percentage error (APE) and the number of training iterations. The following conclusions can be drawn from the results of testing:

- The optimum number of hidden layer neurons for the prediction of cutting forces is 9 ; beyond this number, there is no significant improvement in the error prediction.

- If the training of the ANN is performed at learning rates $(\alpha)$ higher than 0.2 , the network converges to a local minimum instead of the global minimum in the error space. It is set to 0.15 in hidden Layer 1 and 0.17 in Layer 2.

- To minimize the estimation errors, $\beta$ should be between 0.008 and 0.01 . It is set to 0.01 in both hidden layers.

- Networks trained with the ArcTangent transfer function give the least prediction errors, while those employing sigmoid and sine give the highest prediction errors respectively; Networks that employ the sine function require the lowest number of training cycles followed by the ArcTangent.

In Step 3, the training and testing phase is performed. During the training stage, the ANN adjusts its internal structure by adjusting the interconnection weights on the synapses in order to give correct output

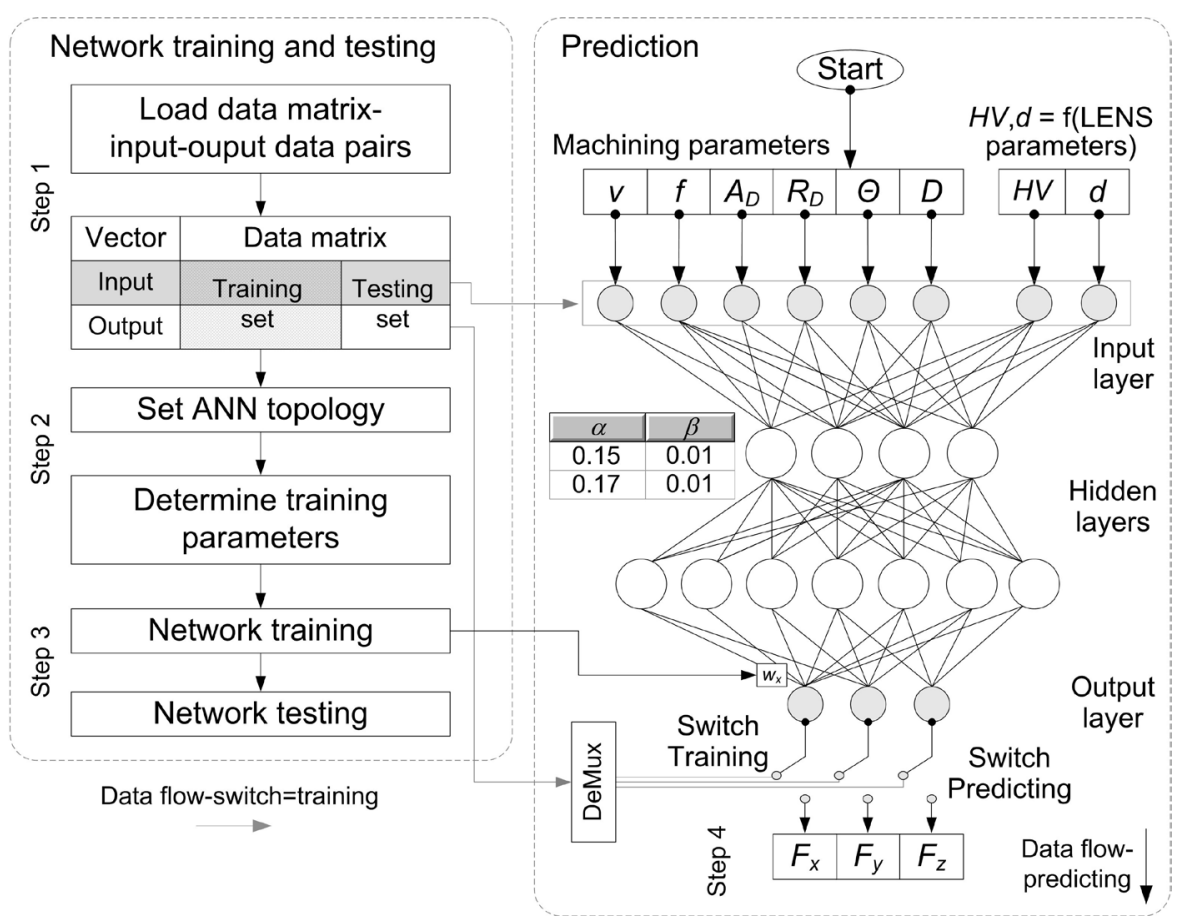

Fig. 1. Flow chart for training and employing the ANN-based cutting force model with its detail structure 
Table 1. 81 datasets for training and testing of neural network (LENS test no. 6)

\begin{tabular}{|c|c|c|c|c|c|c|c|c|c|c|c|c|c|c|c|}
\hline No. & $\begin{array}{c}n \\
{\left[\mathrm{~min}^{-1}\right]}\end{array}$ & $\begin{array}{c}t \\
{[\mathrm{~mm} / \mathrm{min}]}\end{array}$ & $\begin{array}{l}A_{D} \\
{[\mathrm{~mm}]}\end{array}$ & $\begin{array}{l}\Theta \\
{\left[{ }^{\circ}\right]}\end{array}$ & $\begin{array}{l}F_{x} \\
{[\mathrm{~N}]}\end{array}$ & $\begin{array}{l}F_{y} \\
{[\mathrm{~N}]}\end{array}$ & $\begin{array}{l}F_{z} \\
{[\mathrm{~N}]}\end{array}$ & No. & $\begin{array}{c}n \\
{\left[\mathrm{~min}^{-1}\right]}\end{array}$ & $\begin{array}{c}t \\
{[\mathrm{~mm} / \mathrm{min}]}\end{array}$ & $\begin{array}{l}A_{D} \\
{[\mathrm{~mm}]}\end{array}$ & $\begin{array}{l}\Theta \\
{\left[{ }^{\circ}\right]}\end{array}$ & $\begin{array}{l}F_{x} \\
{[\mathrm{~N}]}\end{array}$ & $\begin{array}{l}F_{y} \\
{[\mathrm{~N}]}\end{array}$ & $\begin{array}{l}F_{z} \\
{[\mathrm{~N}]}\end{array}$ \\
\hline 406 & 3000 & 200 & 0.5 & 25 & 181.9 & 179.4 & -59.9 & 448 & 4000 & 250 & 1 & 25 & 106.7 & 129 & -43.4 \\
\hline 407 & 3000 & 200 & 0.5 & 50 & 195.6 & 195 & -65.8 & 449 & 4000 & 250 & 1 & 50 & 99.2 & 117.8 & -39.1 \\
\hline 408 & 3000 & 200 & 0.5 & 75 & 7 & 11.2 & 5.8 & 450 & 4000 & 250 & 1 & 75 & 6.8 & 12.2 & -7.6 \\
\hline 409 & 3600 & 200 & 0.5 & 25 & 89.3 & 104.2 & -34.7 & 451 & 3000 & 300 & 1 & 25 & 190.3 & 205.1 & -68.6 \\
\hline 410 & 3600 & 200 & 0.5 & 50 & 96 & 112.6 & -38.2 & 452 & 3000 & 300 & 1 & 50 & 177 & 184.5 & -63.8 \\
\hline 411 & 3600 & 200 & 0.5 & 75 & 7.2 & 11.8 & 6 & 453 & 3000 & 300 & 1 & 75 & 7.2 & 10.6 & -4.4 \\
\hline 412 & 4000 & 200 & 0.5 & 25 & 38.8 & 59.2 & -20.1 & 454 & 3600 & 300 & 1 & 25 & 151.2 & 158.4 & -53.5 \\
\hline 413 & 4000 & 200 & 0.5 & 50 & 32.9 & 66.32 & -21.7 & 455 & 3600 & 300 & 1 & 50 & 139.1 & 146.9 & -48.7 \\
\hline 414 & 4000 & 200 & 0.5 & 75 & 6.4 & 11.4 & -7.6 & 456 & 3600 & 300 & 1 & 75 & 4.8 & 10.6 & -7.2 \\
\hline 415 & 3000 & 250 & 0.5 & 25 & 193.1 & 186.6 & -61.8 & 457 & 4000 & 300 & 1 & 25 & 102.0 & 151.8 & -49.6 \\
\hline 416 & 3000 & 250 & 0.5 & 50 & 207.6 & 204.9 & -68.7 & 458 & 4000 & 300 & 1 & 50 & 81.1 & 147.8 & -51.1 \\
\hline 417 & 3000 & 250 & 0.5 & 75 & 5.6 & 12.3 & -6.4 & 459 & 4000 & 300 & 1 & 75 & -3.9 & 12.9 & -4.8 \\
\hline 418 & 3600 & 250 & 0.5 & 25 & 105.8 & 119.6 & 40.1 & 460 & 3000 & 200 & 1.5 & 25 & 208.6 & 200.7 & -86.3 \\
\hline 419 & 3600 & 250 & 0.5 & 50 & 117.6 & 130.1 & -43.6 & 561 & 3000 & 200 & 1.5 & 50 & 229.2 & 223 & -75 \\
\hline 420 & 3600 & 250 & 0.5 & 75 & 4.8 & 11.0 & -6.4 & 462 & 3000 & 200 & 1.5 & 75 & 4.4 & 12.6 & -5.6 \\
\hline 421 & 4000 & 250 & 0.5 & 25 & 78.9 & 101.2 & -33.8 & 463 & 3600 & 200 & 1.5 & 25 & 114.1 & 132.9 & -44.6 \\
\hline 422 & 4000 & 250 & 0.5 & 50 & 85.8 & 110.3 & -37.5 & 464 & 3600 & 200 & 1.5 & 50 & 125.4 & 146.9 & -49.5 \\
\hline 423 & 4000 & 250 & 0.5 & 75 & 7.2 & 9.8 & -4.4 & 465 & 3600 & 200 & 1.5 & 75 & 5.2 & 12.2 & -4.4 \\
\hline 424 & 3000 & 300 & 0.5 & 25 & 203.1 & 196.2 & -65.8 & 466 & 4000 & 200 & 1.5 & 25 & 110.4 & 122.8 & -40.5 \\
\hline 425 & 3000 & 300 & 0.5 & 50 & 223.2 & 218.1 & -73.1 & 467 & 4000 & 200 & 1.5 & 50 & 120.3 & 132.9 & -44.0 \\
\hline 426 & 3000 & 300 & 0.5 & 75 & 6.4 & 13.9 & -9.2 & 468 & 4000 & 200 & 1 & 75 & 6.4 & 9.4 & -7.6 \\
\hline 427 & 3600 & 300 & 0.5 & 25 & 121.2 & 133.0 & -44 & 469 & 3000 & 250 & 1 & 25 & 233.7 & 223.9 & -75.5 \\
\hline 428 & 3600 & 300 & 0.5 & 50 & 133.2 & 134.4 & -48.4 & 470 & 3000 & 250 & 1.5 & 50 & 256.8 & 246.1 & -82.1 \\
\hline 429 & 3600 & 300 & 0.5 & 75 & 4.8 & 12.2 & -5.2 & 471 & 3000 & 250 & 1 & 75 & 7.2 & 10.2 & -6.0 \\
\hline 430 & 4000 & 300 & 0.5 & 25 & 88.8 & 130.6 & -42.2 & 472 & 3600 & 250 & 1.5 & 25 & 148.4 & 148.5 & -50.7 \\
\hline 431 & 4000 & 300 & 0.5 & 50 & 99.1 & 138.6 & -47.3 & 473 & 3600 & 250 & 1.5 & 50 & 159.6 & 165 & -55.1 \\
\hline 432 & 4000 & 300 & 0.5 & 75 & 7.2 & -3.6 & -2.4 & 474 & 3600 & 250 & 1.5 & 75 & 4.4 & 11.8 & -5.6 \\
\hline 433 & 3000 & 200 & 1 & 25 & 206.4 & 204.1 & -68.6 & 475 & 4000 & 250 & 1.5 & 25 & 113.2 & 129.2 & -43.7 \\
\hline 434 & 3000 & 200 & 1 & 50 & 189.9 & 187.7 & $\begin{array}{l}-63.8 \\
\end{array}$ & 476 & 4000 & 250 & 1.5 & 50 & 121.0 & 142.6 & -48.1 \\
\hline 435 & 3000 & 200 & 1 & 75 & 6.0 & 9.8 & -6.9 & 477 & 4000 & 250 & 1.5 & 75 & 6.0 & 12.2 & -6.4 \\
\hline 436 & 3600 & 200 & 1 & 25 & 110.2 & 132.6 & -45 & 478 & 3000 & 300 & 1.5 & 25 & 217.6 & 211.1 & -69.5 \\
\hline 437 & 3600 & 200 & 1 & 50 & 101.2 & 118.8 & -41.7 & 479 & 3000 & 300 & 1.5 & 50 & 234.1 & 227.3 & -76.4 \\
\hline 438 & 3600 & 200 & 1 & 75 & 7.6 & 10.6 & -6.8 & 480 & 3000 & 300 & 1.5 & 75 & 6.6 & 11.2 & -5.3 \\
\hline 439 & 4000 & 200 & 1 & 25 & 100.1 & 123.8 & -41.2 & 481 & 3600 & 300 & 1.5 & 25 & 146.3 & 159.3 & -54.1 \\
\hline 440 & 4000 & 200 & 1 & 50 & 90.1 & 114.4 & -37.1 & 482 & 3600 & 300 & 1.5 & 50 & 157.3 & 175.9 & -58.8 \\
\hline 441 & 4000 & 200 & 1 & 75 & 5.6 & 12.2 & -7.6 & 483 & 3600 & 300 & 1.5 & 75 & 6.0 & 10.6 & -6.4 \\
\hline 442 & 3000 & 250 & 1 & 25 & 247.2 & 238 & -79.9 & 484 & 4000 & 300 & 1.5 & 25 & 133.0 & 145.8 & -50.2 \\
\hline 443 & 3000 & 250 & 1 & 50 & 225.6 & 219.0 & -73.5 & 485 & 4000 & 300 & 1.5 & 50 & 143.0 & 162.74 & -54.6 \\
\hline 444 & 3000 & 250 & 1 & 75 & 5.2 & 11.8 & -4.8 & 486 & 4000 & 300 & 1.5 & 75 & 5.6 & 12.6 & -6.4 \\
\hline 445 & 3600 & 250 & 1 & 25 & 145.2 & 153.1 & -51.0 & \multirow{3}{*}{\multicolumn{8}{|c|}{$\begin{array}{l}\text { LENS test no. } 6(P=380 \mathrm{~W}, c=60 \mathrm{~mm} / \mathrm{s}) \\
\text { Cutting tests no. } 136 \text { to } 162 .\end{array}$}} \\
\hline 446 & 3600 & 250 & 1 & 50 & 130.7 & 140.8 & -47.0 & & & & & & & & \\
\hline 447 & 3600 & 250 & 1 & 75 & 6.8 & 9.4 & -7.6 & & & & & & & & \\
\hline
\end{tabular}

results according to the input features. 525 sets of experimental data are used to conduct 500 iterations of training.

Training of the ANN is stopped when the prediction error reaches its global minimum within 500 training iterations. After the ANN had been trained, it was applied to 204 additional input-output data pairs that were excluded from the training process. This time, the values of the output vector were not supplied so that the ANN had to predict them. The predictions were compared to the cutting force measurements and the prediction errors were calculated. It was found out that the error of testing for the 204 examples was 
converged to $4 \%$, which is higher than the error of training $(2.8 \%)$.

Finally, in the fourth step, the trained ANN is used to predict cutting forces. Fig. 1 shows the basic flow chart for training the $\mathrm{ANN}$ and predicting the cutting forces via ANN.

\section{EXPERIMENTAL PROCEDURE AND EQUIPMENT}

To build the ANN model, experimental results were obtained according to the following procedure:

1. Nine four-layered metal workpieces with different layer thicknesses were produced. LENS process parameters at three levels are indicated in Table 2.

2. Thickness $d$ and hardness $H V$ of manufactured layers were measured.

3. The impact of LENS process parameters on the $H V$ and $d$ of the manufactured layer was examined.

4. A total of 243 machining tests were carried out to obtain cutting forces in three directions (Table 2); 27 tests were conducted on each workpiece. Three machining factors at three levels are indicated in Table 1. Each test was repeated three times under the same operating parameters.

5. The results of measured cutting forces were analysed and prepared for ANN training.

Table 2. LENS parameters and corresponding machining tests numbers

\begin{tabular}{ccccc}
\hline $\begin{array}{c}\text { LENS } \\
\text { test }\end{array}$ & $\begin{array}{c}P \\
{[\mathrm{~W}]}\end{array}$ & $\begin{array}{c}c \\
{[\mathrm{~mm} / \mathrm{s}]}\end{array}$ & $\begin{array}{c}\text { Machining test no. } \\
\left(n ; f ; A_{D} ; \Theta\right)\end{array}$ & $\begin{array}{c}\text { ANN data } \\
\text { set no. }\end{array}$ \\
\hline 1 & 300 & 30 & 1 to 27 & 1 to 81 \\
\hline 2 & 300 & 48 & 28 to 54 & 82 to 162 \\
\hline 3 & 300 & 60 & 55 to 81 & 163 to 243 \\
\hline 4 & 380 & 30 & 82 to 108 & 244 to 324 \\
\hline 5 & 380 & 48 & 109 to 135 & 325 to 405 \\
\hline 6 & 380 & 60 & 136 to 162 & 406 to 486 \\
\hline 7 & 400 & 30 & 163 to 189 & 487 to 567 \\
\hline 8 & 400 & 48 & 190 to 216 & 568 to 648 \\
\hline 9 & 400 & 60 & 217 to 243 & 649 to 729 \\
\hline
\end{tabular}

The machining experiments were carried out on the CNC milling machine (type HELLER BEA02), under dry cutting conditions. The cutting forces in the feed $F_{x}$, normal $F_{y}$ and axial directions $F_{z}$ were measured with a Kistler (Type 9257) piezoelectric dynamometer. The dynamometer expresses some limitations since it is conditioned by the vibration of the surrounding system and by the transducer's natural frequency [19]. These parameters could affect the measurement accuracy when measuring cutting forces in high-speed machining. Relevant distortions of cutting force signals are not experienced if low tooth passing frequencies are used [19]. The cutting force measurements experiment in this research showed no need for dynamic compensation at employed, low tooth passing frequencies $(133 \mathrm{~Hz})$. However, to cleanse measured force signals of possible errors induced by vibrations of the surrounding systems, the signals were conditioned through a dual mode charge amplifier (Type 5001) with a low pass filter of $1 \mathrm{kHz}$ cut-off frequency. The used filter is a one pole passive filter with second order Butterworth characteristic. The low pass filter is set to about one-third of the natural frequency of the dynamometer. The analogue force signal is then output to an NI 925A board control by the Labview software. To avoid the distortion, the first natural frequency of the dynamometer has to be at least 3 times higher than the cutting frequency. When the spindle speed is $4000 \mathrm{~min}^{-1}$ using the 2-flute end mill, the cutting frequency is $133 \mathrm{~Hz}$. The natural frequency of the dynamometer should be therefore higher than $400 \mathrm{~Hz}$ to measure cutting force signals at the spindle speed of $4000 \mathrm{~min}^{-1}$. The frequency bandwidth of Kistler 9257 dynamometer is, therefore, adequate for all of the machining cutting-force frequency regimes in this research due to relatively low spindle speeds.

The solid ball-end milling cutting tools (Tornado) of $8 \mathrm{~mm}$ diameter with two cutting edges, of $29.9^{\circ}$ helix angle and $2.28^{\circ}$ rake angle were used. The ballend mills were made of a sintered tungsten carbide material K88UF with the hardness of $1770 \mathrm{HV}$. The cutting edges were coated with PVD-TiAlN coating.

The machining tests were carried out for all combinations of machining parameters and LENS process parameters. One and/or three values for the radial and axial depth of cut have been selected: $R_{D 1}=0.2 \mathrm{~mm} ; A_{D 1}=0.5 \mathrm{~mm}, A_{D 2}=1 \mathrm{~mm}$, $A_{D 3}=1.5 \mathrm{~mm}$. The following values for spindle speed and feed rate have been selected: $n_{1}=3000 \mathrm{~min}^{-1}$, $n_{2}=3600 \mathrm{~min}^{-1}, n_{3}=4000 \mathrm{~min}^{-1} ; f_{1}=200 \mathrm{~mm} / \mathrm{min}$, $f_{2}=250 \mathrm{~mm} / \mathrm{min}, f_{3}=300 \mathrm{~mm} / \mathrm{min}$. The combination of three values for the laser power $(P)$ and the cladding speed $(c)$ was used to make the four-layered material: $P_{1}=300 \mathrm{~W}, P_{2}=380 \mathrm{~W}, P_{3}=400 \mathrm{~W} ; c_{1}=30 \mathrm{~mm} / \mathrm{s}$, $c_{2}=48 \mathrm{~mm} / \mathrm{s}, c_{3}=60 \mathrm{~mm} / \mathrm{s}$.

The workpiece material is made of a $16 \mathrm{MnCr} 5$ basic material and 4 stainless steel (316L) layers with a singular $0.3 \mathrm{~mm}$ to $1.0 \mathrm{~mm}$ thickness, length of $50 \mathrm{~mm}$ and width of $15 \mathrm{~mm}$.

Nine such belts of stainless steel layers were cladded on a singular workpiece with the $60 \mathrm{~mm}$ thickness, length of $180 \mathrm{~mm}$ and width of $70 \mathrm{~mm}$. By varying the two LENS process parameters, 9 different 
test workpieces (9 tests) of four-layered metal material with different layer hardness and thickness were produced on the Optomec LENS 850-R machine. The overlapping in all layers was set to $40 \%$. The diameter of laser ray was $0.8 \mathrm{~mm}$. The experimental setup can be seen in Fig. 2.

The Vickers hardness of manufactured layers was measured by 7061 Zwick 3212 hardness tester. Layer thicknesses $d$ of the manufactured metal material were measured with a Nikon Epiphot 300 Inverted Metallurgical Microscope.

\section{THE IMPACT OF LENS PARAMETERS TO THE HARDNESS AND THICKNESS OF THE MANUFACTURED LAYER}

The results that were obtained from the 9 tests performed on LENS machine are presented in Fig. 3. Two plots have been worked out to determine the

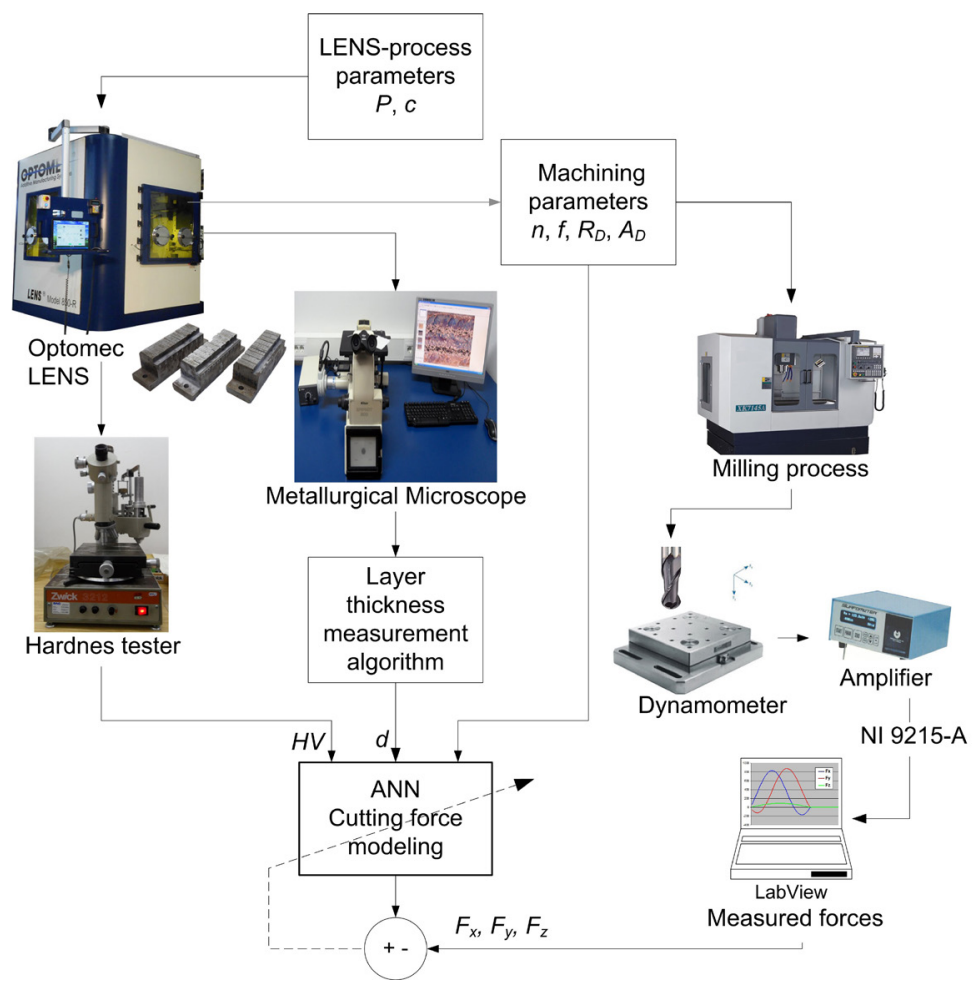

Fig. 2. Experimental set-up

a)

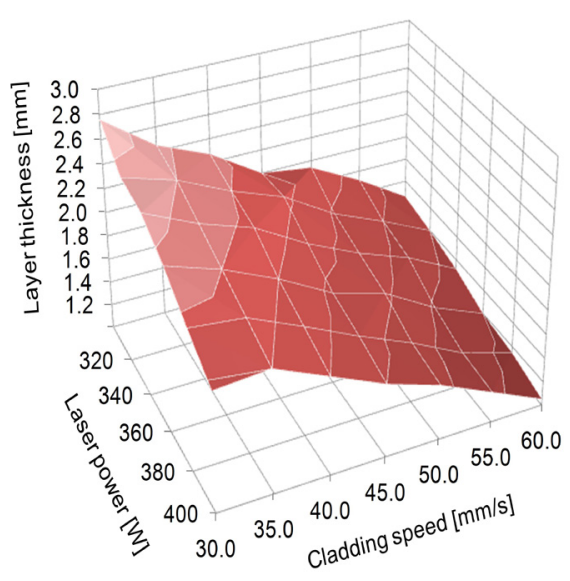

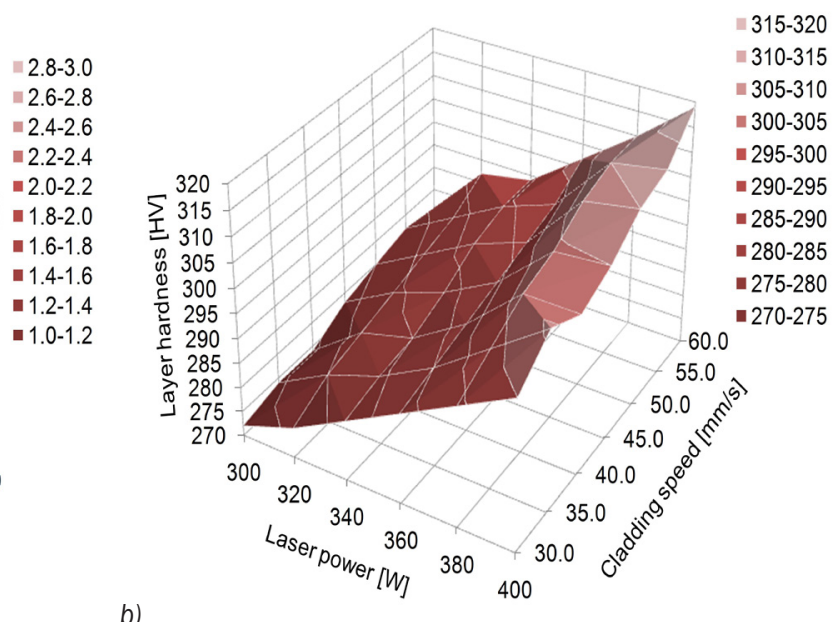

b)

Fig. 3. The impact of LENS parameters to the a) thickness and b) hardness of the manufactured layer 
variation of two LENS parameters with respect to the course of $H V$ and $d$.

In the tests, it was found out that the laser power and a cladding speed have a significant impact on the $H V$ and thickness $d$ of the manufactured layer in the four-layered material.

Fig. $3 b$ indicates that the layer hardness increases from $275 \mathrm{HV}$ to $318 \mathrm{HV}$ when the $P$ increases from $300 \mathrm{~W}$ to $400 \mathrm{~W}$ at the constant cladding speed of 60 $\mathrm{mm} / \mathrm{s}$. Fig. $3 \mathrm{~b}$ shows that the layer hardness increases gradually when the cladding speed increases at the same $P$. The relationship is close to a linear trend.

Fig. 3a shows that the manufactured layer thickness decreases when the cutting power and the cladding speed increases. The relationship is close to a linear trend. It was found out that the cladding speed has the largest impact on manufactured layer thickness.

\section{INFLUENCE FACTORS AND ANALYSIS RESULTS OF MILLING FORCE}

The prediction results and/or the values of measured cutting forces are graphically represented by means of diagrams depending on the angle of rotation of the cutting tool (Fig. 4). Samples of the cutting forces obtained during milling of the four-layered metal material are represented by a continuous line. The force signals outline the tool engagement in $1 / 2$ revolution. Each force signal was obtained by averaging ten onerevolution engagements at different time periods in the cutting test in order to eliminate signal anomalies due to the inhomogeneity of the manufactured stainless steel layers. The force signals clearly outline one characteristic peak corresponding to the engagement of the one flute, separated by periods of no engagement. The rise of the cutting forces in each cycle is due to the increase of chip thickness from zero at the cutting edge entry to a maximum at the exit. The force signal is also influenced by the direction of layer cladding. The order in which the peak forces appear and the spacing between them is also related to the number of manufactured layers and their thickness.

The cutting forces for milling at the ratio $A_{D} / d=0.55$ are relatively higher than expected for milling when the $A_{D} \approx d$ (Fig. 4). Force signals also exhibit more fluctuation. This is probably due to the material inhomogeneity at the border between a)

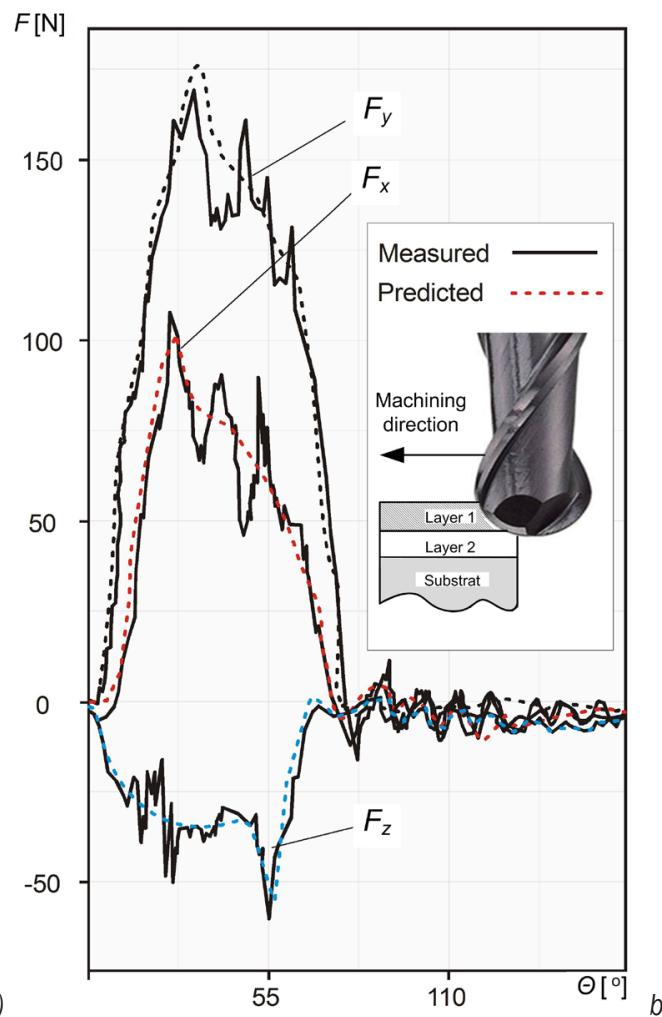

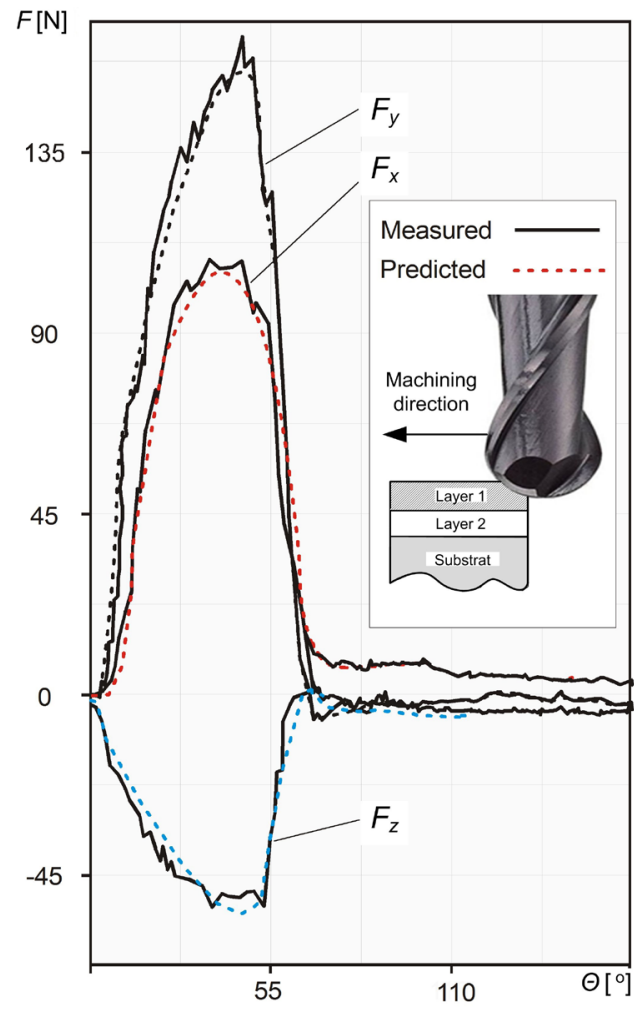

Fig. 4. Comparison between experimental and predicted forces for $16 \mathrm{MnCr} 5 / 316 \mathrm{~L}$ four-layered material at: a) middle depth of cutting $A_{D}=0.45 d$; (test no. 144); b) at high depth of cutting; $A_{D} / \approx d$; (test no. 163) 

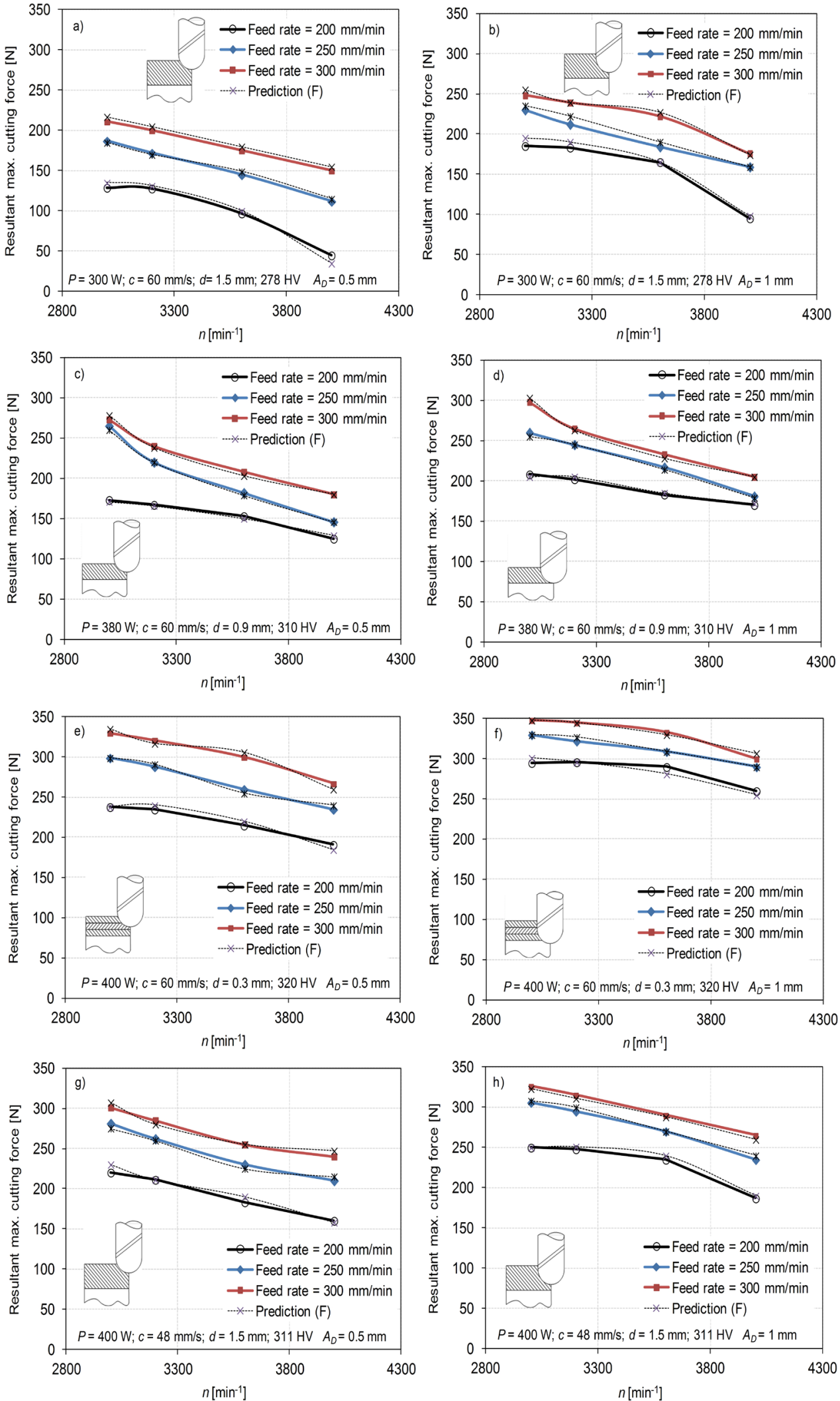

Fig. 5. The effect of LENS and machining parameters to the directions of cutting force; comparison of the maximal values of measured and predicted cutting force 
separate stainless steel layers. The chip obtained in this region is heavily discontinuous and very small. Force fluctuations and magnitude increase slightly as $A_{D}$ becomes larger than $d$.

Plots have been worked out to determine the variation of LENS and machining parameters with respect to the course of the resultant cutting force. A part of these plots were plotted in Fig. 5 to present the relationship of these operating parameters.

Fig. 5 shows that the cutting force decreases when the spindle speed increases at the same feed rate and depth of cut. The relationship is close to a linear trend. It was found that feed rate has the largest impact on cutting force.

The cutting force decreases when the feed rate decreases. It is also obvious that the force signal for the multi-layered material is characteristic of the architecture of the material, which depends on the LENS machine settings. Figs. 5a to $\mathrm{f}$ indicate that the cutting force increases significantly (up to $60 \%$ ) when the $P$ setting increases from $300 \mathrm{~W}$ to $400 \mathrm{~W}$ at the constant $c(60 \mathrm{~mm} / \mathrm{s})$ and constant machining parameters.

Figs. 5e and $\mathrm{g}$ outline that the $F$ increases moderately (for $16 \%$ ) when the c increases from $48 \mathrm{~mm} / \mathrm{s}$ to $60 \mathrm{~mm} / \mathrm{s}$ at the constant $P(400 \mathrm{~W})$ and $A_{D}$. The analysis of the plots indicate that two-way (dual) effect interaction $P \times c$ has a significant effect on the value of the resultant cutting force $F$. It could be observed from Fig. 5 that the laser power setting has the second largest impact on the cutting force.

Figs. $5 \mathrm{~b}, \mathrm{~d}$, and $\mathrm{f}$ indicate that the cutting force increases significantly (by $40 \%$ ) when the manufactured layer thickness decreases $(1.5 \mathrm{~mm}$ down to $0.3 \mathrm{~mm}$ ) at the same cutting parameters.

By comparing Figs. $5 \mathrm{f}$ and $\mathrm{g}$, it is found that when cutting with constant $A_{D}=1 \mathrm{~mm}$ at the ratio $A_{D} / d=3.3$, the cutting forces are $8 \%$ higher in comparison to cutting at the ratio $A_{D} / d=0.6$. Therefore, the cutting forces are higher when the cutting involves more than one layer.

\section{MODELING RESULTS AND DISCUSSION}

Several experimental tests have been performed in order to validate the developed ANN model for different cutting conditions and LENS machine parameters.

The partial testing results of the ANN model are shown in Fig. 5. The results include data in which LENS parameters are different. The eight graphs on Fig. 5 compare the predicted values and measured values of maximal cutting forces. It could be observed from Fig. 5 that the predicted values of cutting force are very close to the experimental measurement values. The maximum percentage prediction cutting force error is found to be less than $4.8 \%$ for all the cases tested.

A criterion in this experiment used to judge the efficiency of the model was the APE error, defined as:

$$
A P E=\frac{\sum_{i=1}^{m} \frac{\left|F^{\sim}{ }_{i}-F_{i}\right|}{F_{i}^{\sim}} \cdot 100 \%}{m},
$$

where $F \sim_{i}$ is the actual cutting force component measured by the dynamometer, $F_{i}$ is the predicted cutting force component generated by ANN and $m$ is the size of sample data.

An example of test conditions for one LENS machine setting (LENS test no. 6) and cutting test no. 144 and 163 are given in Table 3. Table 3 lists the input and output of the prediction model results for cutting conditions, cutting tool rotation, layer thickness and cutting force components. It compares the experimental data and the predicted values of the cutting force components after training of the ANN model. The results mutually differ as follows: from $0.9 \%$ to $4.7 \%$ for $F_{x}$, from $0.3 \%$ to $4.5 \%$ for $F_{y}$ and from $0.7 \%$ to $3.7 \%$ for $F_{z}$. Graphical comparisons between the experimental cutting forces and the predicted cutting forces for a machining example are shown in Fig. 4.

The results in Figs. $4 \mathrm{a}$ and $\mathrm{b}$ show that the ANN model provides good agreement with experimental results. The greatest difference between predictions and experimental results appear in the normal force on the boundary region between two cladded stainless steel layers (Fig. 4b). From Figs. 4a and $b$ it can be seen that the values from prediction coincide well with the values from the experiments and, in addition, the process of the change of the cutting force with respect to the angle of rotation of the milling cutter and the amplitude agree well, with only slight differences in the peak and valley regions. The slight differences between the simulated and measured results are believed to be caused by the cutter runout, which is evident from the repeated tooth passing patterns in the measured forces. Fig. 6 shows the scatter diagram of the predicted values and measurement values of the $F_{x}, F_{y}$ and $F_{z}$ cutting forces of 100 sets of testing data. It shows that the predicted values of cutting forces follow the $45^{\circ}$ line very closely. The predicted values are very close to the experimental measurement values. If the model is used outside training parameters or if the conditions are changed (tool/ 
Table 3. Cutting force predictions, measurements, and APE errors for experiment with constant LENS machine settings (LENS test no. 6; $P=$ $380 \mathrm{~W}, \mathrm{c}=60 \mathrm{~mm} / \mathrm{min})$

\begin{tabular}{|c|c|c|c|c|c|c|c|c|c|}
\hline$n$ [min-1] & $A_{D}[\mathrm{~mm}]$ & $R_{D}[\mathrm{~mm}]$ & $f[\mathrm{~mm} / \mathrm{min}]$ & $d[\mathrm{~mm}]$ & $H V$ & \multirow{2}{*}{\multicolumn{4}{|c|}{$\begin{array}{l}\text { Cutting test no. 144; } \\
\text { ANN data set no. 460-432 }\end{array}$}} \\
\hline 4000 & 0.5 & 0.2 & 300 & 0.9 & 310 & & & & \\
\hline \multirow{2}{*}{$\begin{array}{c}\text { Angle of cutting } \\
\text { tool rotation } \\
\Theta\left[^{\circ}\right]\end{array}$} & \multicolumn{2}{|c|}{ Cutting force } & \multirow[b]{2}{*}{$\begin{array}{c}\text { Error } \\
{[\%]}\end{array}$} & \multicolumn{2}{|c|}{ Cutting force } & \multicolumn{3}{|c|}{ Cutting force } & \multirow[b]{2}{*}{ Error [\%] } \\
\hline & $\begin{array}{l}\text { Measured } \\
F_{x}[\mathrm{~N}]\end{array}$ & $\begin{array}{l}\text { Predicted } \\
F_{x}[\mathrm{~N}]\end{array}$ & & $\begin{array}{c}\text { Measured } \\
F_{y}[\mathrm{~N}]\end{array}$ & $\begin{array}{c}\text { Predicted } \\
F_{y}[\mathrm{~N}] \\
\end{array}$ & Error [\%] & $\begin{array}{l}\text { Measured } \\
F_{z}[\mathrm{~N}]\end{array}$ & $\begin{array}{c}\text { Predicted } \\
F_{z}[\mathrm{~N}]\end{array}$ & \\
\hline 25 & 88.8 & 91.9 & 3.51 & 130.6 & 133.54 & 2.25 & -42.2 & -40.98 & 2.88 \\
\hline 50 & 99.1 & 103.7 & 4.68 & 138.6 & 142.84 & 3.06 & -47.3 & -46.07 & 2.6 \\
\hline 75 & 7.2 & 7.1 & 1.03 & -3.6 & -3.64 & 1.12 & -2.4 & -2.32 & 3.21 \\
\hline$n$ [min-1] & $A_{D}[\mathrm{~mm}]$ & $R_{D}[\mathrm{~mm}]$ & $f[\mathrm{~mm} / \mathrm{min}]$ & $d[\mathrm{~mm}]$ & $H V$ & \multirow{2}{*}{\multicolumn{3}{|c|}{$\begin{array}{c}\text { Cutting test no. 163; } \\
\text { ANN data set no. 457-459 }\end{array}$}} & \\
\hline 4000 & 1 & 0.2 & 300 & 0.9 & 310 & & & & \\
\hline \multirow{2}{*}{$\begin{array}{c}\text { Angle of cutting } \\
\text { tool rotation } \\
\Theta\left[^{\circ}\right]\end{array}$} & \multicolumn{2}{|c|}{ Cutting force } & \multirow[b]{2}{*}{$\begin{array}{c}\text { Error } \\
{[\%]}\end{array}$} & \multicolumn{2}{|c|}{ Cutting force } & & \multicolumn{2}{|c|}{ Cutting force } & \\
\hline & $\begin{array}{l}\text { Measured } \\
F_{x}[\mathrm{~N}]\end{array}$ & $\begin{array}{c}\text { Predicted } \\
F_{x}[\mathrm{~N}]\end{array}$ & & $\begin{array}{c}\text { Measured } \\
F_{y}[\mathrm{~N}]\end{array}$ & $\begin{array}{c}\text { Predicted } \\
F_{y}[\mathrm{~N}]\end{array}$ & Error [\%] & $\begin{array}{c}\text { Measured } \\
F_{z}[\mathrm{~N}]\end{array}$ & $\begin{array}{c}\text { Predicted } \\
F_{z}[\mathrm{~N}]\end{array}$ & Error [\%] \\
\hline 25 & 102.0 & 101.0 & -0.95 & 151.8 & 153.48 & 1.11 & -49.6 & -48.33 & 2.56 \\
\hline 50 & 81.1 & 78.8 & 2.89 & 147.8 & 152.32 & 3.06 & -51.1 & -51.62 & 1.01 \\
\hline 75 & -3.9 & -3.7 & -4.5 & 12.9 & 13.20 & 2.34 & -4.8 & -4.70 & 2.02 \\
\hline
\end{tabular}
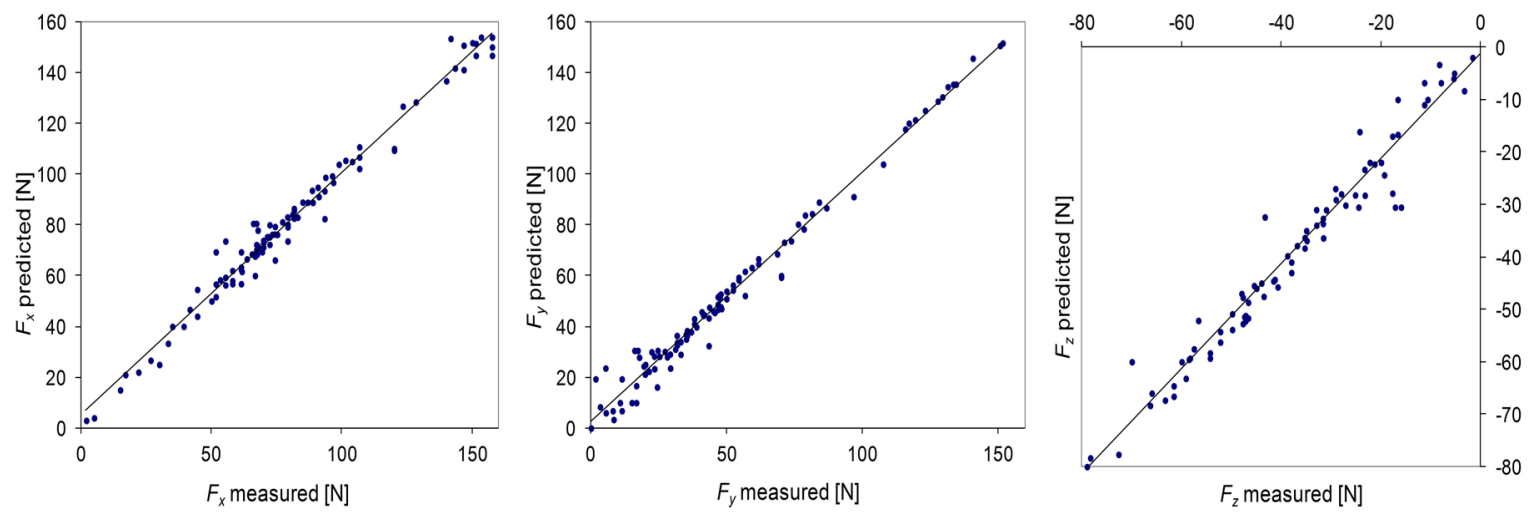

Fig. 6. Scatter diagram of predicted and measured forces for testing data set

workpiece combination), the ANN model has to be adapted via additional training with new experimental data in order to remain valid.

The reliability of an ANN model is determined by two factors: extrapolation and the local areas of poor fit. Finding exact reliability in multi-layered backpropagation network (BPN) is a non-deterministic polynomial-time hard (NP-Hard) problem [20], because BPNs do not have inherent ability to indicate the extrapolation and to calculate confidence limits on their predictions. If one attempted to train a BPN to recognize extrapolation, a comprehensive set of examples representing extrapolation would be needed. Forming such a training set is tantamount to solving the extrapolation problem in advance [20]. It is conceivable to add auxiliary outputs to a BPN to produce the output confidence intervals. However, this approach is also not efficient because of the need for extensive additional training [20].

\section{CONCLUSIONS}

The present research outlines the experimental investigation of cutting forces during computer numerical control (CNC) end-milling operation of four-layered metal material. Based on the experimental data the ANN approach was developed to predict the cutting forces while machining. Hardness and thickness of the particular manufactured layer in multi-layered metal material has been included in the input vector of the prediction model in order to improve the accuracy of predictions. The following conclusions can be drawn: 
- Laser power and cladding speed have the largest impact on the hardness and thickness of the manufactured layer in the four-layered metal material.

- The layer thickness has a significant influence on predicted cutting forces.

- The cutting forces for milling at the ratio $A_{D} / d=0.55$ are relatively higher than expected for milling when the $A_{D} \approx d$. Force signals also exhibit more fluctuation. This is probably due to the material inhomogeneity at the border between separate stainless steel layers. The chip obtained in this region is heavily discontinuous and very small. Force fluctuations and magnitude increase slightly as $A_{D}$ becomes larger than $d$.

- The majority of the predicted cutting force values are equivalent to the appurtenant experimental values with negligible error.

Future activities will be carried out to implement the ANN model to the tool shop environment and to upgrade it with different tool/workpiece combinations.

\section{REFERENCES}

[1] Mahmoud, E.R.I. (2015). Characterizations of 304 stainless steel laser cladded with titanium carbide particles. Advances in Production Engineering \& Management, vol. 10, no. 6, p. 115-124, D0I:10.14743/apem2015.3.196.

[2] Jahromi, A.S., Bahr, B. (2010). An analytical method for predicting cutting forces in orthogonal machining of unidirectional composites. Composites Science and Technology, vol. 70, no. 16, 2290-2297, D0l:10.1016/j. compscitech.2010.09.005.

[3] Sui, X.L., Zhang, J.T., Ge, J.H., Wang, Y. P. (2008). Modeling and simulation of milling force in virtual numerical control milling process. Key Engineering Materials, vol. 392, p. 697-702.

[4] Zhou, H.M., Deng, J.X., Xie, W.W. (2010). Milling force forecast of the matching of lengthened shrink-fit holder and cutter in high speed machining. Advanced Materials Research, vol. 139-141, p. 827-830, D0l:10.4028/www.scientific.net/ AMR.139-141.827.

[5] Milfelner, M., Cus, F. (2003). Simulation of cutting forces in ball-end milling. Robotics and Computer-Integrated Manufacturing, vol. 19, no. 1-2, p. 99-106, Dol:10.1016/ S0736-5845(02)00066-2.

[6] Aykut, Ş., Gölcü, M., Semiz, S., Ergür, H.S. (2007). Modeling of cutting forces as function of cutting parameters for face milling of satellite 6 using an artificial neural network. Journal of Materials Processing Technology, vol. 190, no. 1-3, p. 199203, DOI:10.1016/j.jmatprotec.2007.02.045.

[7] Zuperl, U., Cus, F., Reibenschuh, M. (2012). Modeling and adaptive force control of milling by using artificial techniques. Journal of Intelligent Manufacturing, vol. 23, no. 5, p. 18051815, DOI:10.1007/s10845-010-0487-z.

[8] Klancnik, S., Ficko, M., Balic, J., Pahole, I. (2015). Computer vision-based approach to end mill tool monitoring.
International Journal of Simulation Modelling, vol. 14, no. 4, p. 571-583, D0I:10.2507/IJSIMM14(4)1.301.

[9] Zuperl, U., Cus, F., Mursec, B., Ploj, T. (2006). A generalized neural network model of ball-end milling force system. Journal of Materials Processing Technology, vol. 175, no. 1-3, p. 98108, D0l:10.1016/j.jmatprotec.2005.04.036.

[10] Das, B., Roy, S., Rai, R.N., Saha, S.C. (2016). Study on machinability of in situ Al-4.5\% CU-TiC metal matrix composite-surface finish, cutting force prediction using ANN. CIRP Journal of Manufacturing Science and Technology, vol. 12, p. 67-78, D0l:10.1016/j.cirpj.2015.10.002.

[11] Dave, H.K., Raval, H.K. (2010). Modelling of cutting forces as a function of cutting parameters in milling process using regression analysis and artificial neural network. International Journal of Machining and Machinability of Materials, vol. 8, no. 1-2, p. 198-208, D0I:10.1504/IJMMM.2010.034496.

[12] El-Mounayri, H., Kishawy, H., Briceno, J. (2005). Optimization of CNC ball end milling: a neural network-based model. Journal of Materials Processing Technology, vol. 166, no. 1, p. 50-62, D0l:10.1016/J.jmatprotec.2004.07.097.

[13] Navarro, H., Bennun, L. (2014). Descriptive examples of the limitations of artificial neural networks applied to the analysis of independent stochastic data. International Journal of Computer Engineering \& Technology, vol. 5, p. 40-42.

[14] M'Saoubi, R., Axinte, D., Soo, S. L., Nobel, C., Attia, H., Kappmeyer, G., Engin, S., Sim, W.M. (2015). High performance cutting of advanced aerospace alloys and composite materials. CIRP Annals-Manufacturing Technology, vol. 64, no. 2, p. 557-580, Dol:10.1016/j.cirp.2015.05.002.

[15] Tabernero, I., Lamikiz, A., Martínez, S., Ukar, E., Figueras, J. (2011). Evaluation of the mechanical properties of Inconel 718 components built by laser cladding. International Journal of Machine Tools and Manufacture, vol. 51, no. 6, p. 465-470, D0l:10.1016/j.ijmachtools.2011.02.003.

[16] Shokrani, A., Dhokia, V., Newman, S.T. (2012). Environmentally conscious machining of difficult-to-machine materials with regard to cutting fluids. International Journal of Machine Tools and Manufacture, vol. 57, p. 83-101, D0l:10.1016/j. ijmachtools.2012.02.002.

[17] Koyilada, B., Gangopadhyay, S., Thakur, A. (2016). Comparative evaluation of machinability characteristics of Nimonic C-263 using CVD and PVD coated tools. Measurement, vol. 85, p. 152-163, D0I:10.1016/j.measurement.2016.02.023.

[18] Dong, G., Zhaopeng, H., Rongdi, H., Yanli, C., Muguthu, J.N. (2011). Study of cutting deformation in machining nickel-based alloy Inconel 718. International Journal of Machine Tools and Manufacture, vol. 51, no. 6, p. 520-527, D0I:10.1016/j.ijmachtools.2011.02.011.

[19] Scippa, A., Sallese, L., Grossi, N., Campatelli, G. (2015). Improved dynamic compensation for accurate cutting force measurements in milling applications. Mechanical Systems and Signal Processing, vol. 54-55, p. 314-324, D0l:10.1016/j. ymssp.2014.08.019.

[20] Kaushik, B., Banka, H. (2015). Performance evaluation of approximated artificial neural network (AANN) algorithm for reliability improvement. Applied Soft Computing, vol. 26, p. 303-314, Dol:10.1016/j.asoc.2014.10.002. 